\title{
Mikroorganizmaların Büyüme Eğrilerini Tanımlamak İçin Excel Tabanlı, Kullanıcı Dostu, Ücretsiz Bir Araç: ÖK-BUZ GRoFiT
}

\author{
An Excel-based, User-friendly Freeware Tool to Describe Microbial Growth Curves: ÖK-BUZ \\ GRoFiT
}

\section{Hasan Basri ÖKSÜZ1 ${ }^{1}$, Sencer BUZRUL ${ }^{2 *}$}

\section{$\ddot{O} \mathbf{z}$}

$\mathrm{Bu}$ çalışmada mikroorganizmaların (bakteriler, mayalar, küfler) büyüme/gelişme eğrilerini tanımlamak için Excel $^{\circledR}$ tabanlı ücretsiz bir araç olan ÖK-BUZ (Öksüz-Buzrul) GRoFiT (büyüme eğrileri tanımlama) uygulamasının kullanımı gösterilmiş̧ir. Günümüzde birçok büyüme modeli kullanılmakta olup, bunların içerisinden belki de en fazla kullanılan büyüme modellerinden olan Baranyi, Gompertz ve Üç Fazlı Doğrusal (ÜFD) modelleri Excel içerisine yerleştirilerek, modelleme konusunda çok yetkin olmayan kişilerin de rahatlıkla kullanabileceği ve sonuçları yorumlayabileceği kullanıcı dostu bir araç oluşturulmuştur. Bu araç kullanılarak her üç modelin parametreleri yani mikroorganizmaların başlangıç sayısı $\left(\log _{10} N_{0}\right)$, mikroorganizmaların ulaşabileceği azami sayı $\left(\log _{10} N_{\text {maks }}\right)$, azami özgül büyüme hızı $\left(\mu_{\text {maks }}\right.$ veya $\mu$ ) ve uyum (lag) zamanı $(\lambda)$ standart hatalarıyla birlikte bulunabilir. Dahası model parametrelerinin üst ve alt sınırları (\%95 güven aralıkları) da elde edilebilmektedir. $\mathrm{Bu}$ değerlerin hemen yanında model uyum göstergeleri listelenmektedir. Bunlar belirleme katsayıs $\left(\mathrm{R}^{2}\right.$ ), ayarlı belirleme katsayısı (ayarlı $\mathrm{R}^{2}$ ) ve modelin standart hatası veya karesel ortalama hatadır (RMSE). Araç içerisindeki modeller birçok farklı büyüme veri setine uygulanmış ve sonuçlar ücretli bir yazılım olan SigmaPlot ${ }^{\mathbb{R}}$ programı ile karşılaştırılmıştır. Karşılaştırma sonucunda rahatlıkla söylenebilir ki bu uygulamanın mikroorganizmaların büyüme eğrilerini tanımlaması bakımından paralı yazılımlardan farkı yoktur: ÖK-BUZ GRoFiT kullanılarak aynı veri seti için aynı parametre değerlerini ve aynı model uyum göstergelerini elde etmek mümkündür. Ayrıca, ÖK-BUZ GRoFiT Monte Carlo benzetimi yaparak ücretli programların birçoğunda bulunmayan simetrik olmayan $\% 95$ güven aralıklarını da hesaplamaktadır. Parametrelerin güven aralıklarını hesaplayabilen ücretli yazılımlar ise genel olarak simetrik güven aralıklarını vermektedir. ÖK-BUZ GRoFiT uygulaması tamamen Türkçe olup, "https://mmf.gidatarim.edu.tr/ok-buz-grofit" adresinden ücretsiz olarak indirilerek kullanılabilir. Kullanıcılardan gelecek olan talepler doğrultusunda uygulama içerisine yeni büyüme modelleri de eklenebilecek ve farklı disiplinlerde çalışan araştırmacıların (gıda, kimya, biyoloji, ziraat, biyoteknoloji vb.) bu uygulamayı kullanması mümkün olacaktır.

Anahtar Kelimeler: Doğrusal olmayan regresyon, Model uyumu, Model tahmini, Baranyi, Gompertz

\footnotetext{
${ }^{1}$ Hasan Basri Öksüz, Elektrik-Elektronik Mühendisliği Bölümü, Konya Gıda ve Tarım Üniversitesi, Meram/Konya E-mail: hasan.oksuz@gidatarim.edu.tr OrcID: 0000-0001-5740-8793

2 *Sorumlu Yazar/Corresponding Author: Sencer Buzrul, Gıda Mühendisliği Bölümü, Konya Gıda ve Tarım Üniversitesi, Meram/Konya E-mail: sencer.buzrul@, gidatarim.edu.tr (D) OrcID: 0000-0003-2272-3827

Atıf/Citation: Öksüz, H.B., Buzrul S. Mikroorganizmaların Büyüme Eğrilerini Tanımlamak İçin Excel Tabanlı, Kullanıcı Dostu, Ücretsiz Bir Araç: ÖK-BUZ GRoFiT. Tekirdağ Ziraat Fakültesi Dergisi, 18 (3), 521-532.

*Bu çalışma Yüksek Lisans tezinden özetlenmiştir.

CBu çalışma Tekirdağ Namık Kemal Üniversitesi tarafından Creative Commons Lisansı (https://creativecommons.org/licenses/by-nc/4.0/)

kapsamında yayınlanmıştır. Tekirdağ 2021
} 


\begin{abstract}
The use of an Excel ${ }^{\mathbb{B}}$-based free tool, ÖK-BUZ (Öksüz-Buzrul) GRoFiT (growth curves fitting) application, was demonstrated to describe the growth curves of microorganisms (bacteria, yeasts, molds) in this study. Several different microbial growth models are being used today, Baranyi, Gompertz and Three Phase Linear (TPL) models, which are perhaps among the most used growth models, were placed in Excel, and a user-friendly tool has been created that can be used by researchers who are not very competent in modeling and interpreting the results. Model parameters, namely the initial number of microorganisms $\left(\log _{10} N_{0}\right)$, the maximum number of microorganisms can reach $\left(\log _{10} N_{\max }\right)$, the maximum specific growth rate $\left(\mu_{\max }\right.$ or $\left.\mu\right)$ and the adaptation (lag) time $(\lambda)$ together with their standard errors can be obtained by using this tool. Moreover, upper and lower limits $(95 \%$ confidence intervals) of the model parameters can also be found. The goodness-of-fit indicators are listed next to these values. These are the coefficient of determination $\left(R^{2}\right)$, the adjusted coefficient of determination $\left(\mathrm{R}_{\text {adj }}^{2}\right)$ and the standard error of the model or the root mean square error (RMSE). The models in the tool were applied to several different growth data and the results were compared with SigmaPlot ${ }^{\mathbb{R}}$ program, which is a shareware. As a result of this comparison, it can be safely said that this tool is no different from shareware in terms of describing the growth curves of microorganisms: It is possible to obtain the same parameter values and goodness-of-fit indices for the same data set. Further ÖK-BUZ GRoFiT applies Monte Carlo simulation to calculate the unsymmetrical confidence intervals which cannot be done by most of the sharewares. The sharewares, which can calculate the confidence intervals of the parameters, give the symmetrical confidence intervals in general. The application is in Turkish and it can be used by downloading it for free from the web page "https://mmf.gidatarim.edu.tr/ok-buzgrofit". The new growth models can be added into the application in line with the demand of the users and it may be possible to use this application for the researchers working in different disciplines (food, chemistry, biology, agriculture, biotechnology etc.).
\end{abstract}

Keywords: Non-linear regression, Model fit, Model prediction, Baranyi, Gompertz 


\section{Giriș}

Son yıllarda tüketicilerin yiyecek ve içecekleri konusunda oldukça dikkatli olması gıda güvenliğinin önemini artırmıştır (Niyaz ve Demirbaş, 2018). Günümüz gıda sanayiinde "güvenli gıda" ifadesi tüketiciye ulaşmak için sıklıkla kullanılmaktadır (Arıcı, 2006). Gıdaların üretimden dağıııma kadar özellikle mikrobiyolojik olarak güvenli olması gıda sanayiinin üzerinde önemle durduğu bir konudur. Uygun olmayan sıcaklık koşullarında bazı gıdalarda mikroorganizmalar üreyebilir. Bu mikroorganizmaların bir kısmı gıdanın bozularak tüketilemeyecek hale gelmesine neden olurken bazıları da hastalığa (örneğin Salmonella ve Listeria monocytogenes gibi patojenler) yol açabilirler. $\mathrm{Bu}$ nedenle gıda güvenliği açısından mikroorganizmaların büyüme ya da gelişme kinetiğinin çalışılması gereklidir.

Gıdanın içerisinde ya da kapalı bir sistemde (örneğin sıvı besiyeri) büyüyen mikroorganizmalarda genellikle 4 faz veya evre görülür (Şekil l) (Özçelik ve ark., 2019). Birincisi uyum sağlama ya da adaptasyon evresi olarak adlandırılır ve mikroorganizmaların yeni bir ortama uyum gösterip çoğalmaya başlayana kadar geçen süre $(\lambda)$ olarak ifade edilir. Bu evrede bakterilerin hücre artışı gözlemlenmezken, hücre kütlesi artabilir. İkinci evre çoğalma evresi olup, mikroorganizmalar bu evrede üstel (logaritmik) olarak çoğalırlar. Bu evrede mikroorganizmalar azami büyüme hızına $\left(\mu_{\text {maks }}\right)$ ulaşırlar ancak bu evrenin sonlarına doğru büyüme hızı da yavaşlar çünkü mikroorganizmalar kapalı bir sistemde ulaşabilecekleri azami sayıya $\left(10^{8}\right.$ ve $10^{9}$ hücre $\left.\mathrm{mL}^{-1}\right)$ ulaştıklarından ortamda besinler giderek azalmaktadır. Ayrıca ortamda toksik etken olabilecek metabolik maddeler birikmektedir. Üçüncü evre durma evresidir ve gittikçe kısıtlanan koşullar nedeniyle büyüme devam edemez. Durma evresi gelişme eğrisinde düz seyreden yatay bir çizgi şeklindedir. Son evre olan ölüm evresinde ise canlı hücre sayısında azalma görülür (Özçelik ve ark., 2019). Mikrobiyal büyüme modelleri sadece ilk üç evreyi (uyum, çoğalma ve durma) tanımlamak için kullanılır çünkü bir gıdada ölüm evresine gelinmişse o gıdanın güvenilirliği tartışmalıdır.

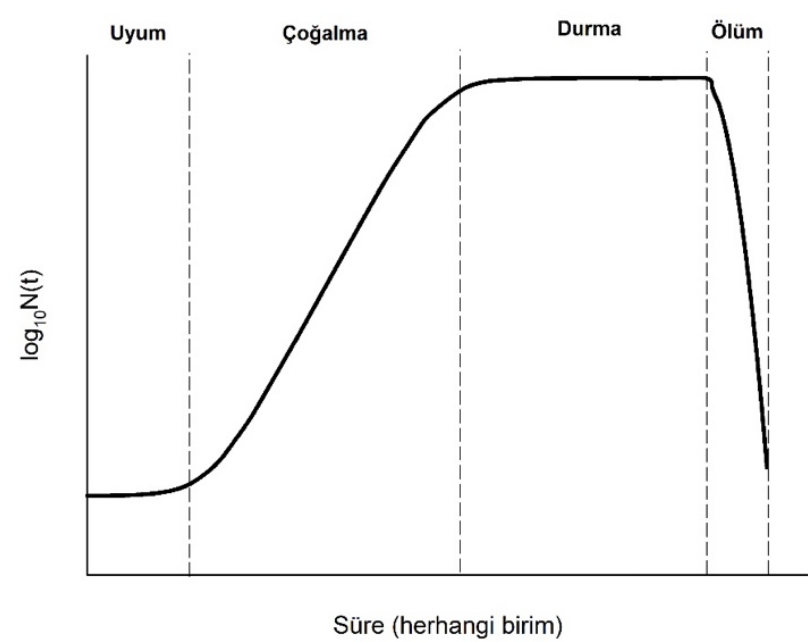

Figure 1. Growth curves of microorganisms that grow in a closed habitat

\section{Şekil 1. Kapalı bir ortamda büyüyen mikroorganizmaların büyüme ya da gelişme ĕgrisi}

Günümüzde birçok mikrobiyal büyüme modeli önerilmiş ve kullanılmaktadır. Ancak bunlardan belki de en çok tercih edilenleri Gompertz (Zwietering ve ark., 1990), Baranyi (Baranyi ve Roberts, 1994) ve üç fazlı doğrusal (Buchanan ve ark., 1997) modelleridir (Öksüz ve Buzrul, 2020). Bu modeller arasında seçim yapmak veya hangi modelin daha iyi olduğuna karar vermek, bunun ötesinde model parametrelerini elde etmeye çalışmak bir takım matematiksel ve istatistiksel bilgi gerektirmektedir. Ancak, özellikle de biyolojik bilimler ve gıda bilimleri alanında çalışanların bir kısmı bu bilgilerden yoksun kalabilmektedir. Bu kişiler için Excel tabanlı kullanıcı dostu bazı uygulamalar vardır. Örneğin DiMFiT uygulaması Excel eklentisi olarak, modelleme konusunda yeterli bilgiye sahip olmayanlar için Baranyi modelinin mikrobiyal büyüme verilerini tanımlamak için kullanılabilir. Bu uygulama herkese açık ve ücretsiz olup internetten indirilerek kullanılabilir. Bir diğer Excel tabanlı uygulama Fujikawa ve Kano (2010) tarafından sunulan farklı bir büyüme modeli içeren programdır. Ancak, bu yazılım 
Mikroorganizmaların Büyüme Eğrilerini Tanımlamak İçin Excel Tabanlı, Kullanıcı Dostu, Ücretsiz Bir Araç: ÖK-BUZ GRoFiT

DiMFiT gibi herkesin erişimine açık değildir. Üstelik her iki uygulamada da tek bir büyüme modeli yer almakta ve model parametrelerinin standart hataları ya da güven aralıkları elde edilememektedir. Sadece mikrobiyal büyüme için değil ölüm kinetiği için de benzer excel tabanlı uygulamalar yer almaktadır. Örneğin GInaFiT uygulaması içerisinde birçok inaktivasyon modeli barındıran Excel-tabanlı bir eklentidir (Geeraerd ve ark., 2005).

$\mathrm{Bu}$ çalışmanın amacı, matematik modelleme konusunda yeterince bilgisi olmayanların da rahatça kullanabileceği ve sonuçları yorumlayabileceği, mikroorganizmaların büyüme eğrilerini tanımlamak için Excel tabanlı ücretsiz bir araç olan ÖK-BUZ GRoFiT uygulamasının kullanımını göstermektir. Uygulamanın Excel tabanlı yapılmasının sebebi deneysel verilerle uğraşan araştırmacıların birçoğunun M.S. Office Excel'e erişiminin olmasıdır. Bu doğrultuda öncelikle uygulamada kullanılan büyüme modelleri tanıtılacak, daha sonra da uygulamanın kullanımı anlatılacaktır.

\section{Materyal ve Metot}

\subsection{Mikrobiyal büyüme parametreleri}

Kapalı bir sistemde çoğalma evresinde mikrobiyal büyüme aşağıdaki eşitlik 1 ile ifade edilir (Baranyi ve Roberts, 1994);

$$
\frac{d N(t)}{d t}=\mu_{m a k s} \cdot N
$$

Burada, $N(t)$ mikroorganizmaların $t$ zamandaki sayısı, $\mu_{\text {maks }}$ ise azami özgül mikrobiyal büyüme hızıdır. Bu basit diferansiyel denklem çözülürse aşağıdaki sonuç elde edilir (Eş.2);

$$
\ln N(t)=\ln N_{0}+\mu_{m a k s} \cdot t
$$

Bu eşitlikte de $N_{0}$ mikroorganizmaların başlangıç zamanındaki $(t=0)$ sayısıdır. Mikrobiyal büyüme genellikle 10 tabanındaki logaritma ile ifade edildiğinden (Eş.3);

$$
\log _{10} N(t)=\log _{10} N_{0}+\frac{\mu_{\text {maks }}}{2.303} \cdot t
$$

yazılabilir. Bu denklemde $\ln 10 \approx 2.303$ 'tür. Azami büyüme hızı $\log _{10}$ tabanında $\mu^{\prime}$ maks $\left(\mu_{\text {maks }} / 2.303\right)$ olarak ifade edilebilir.

Büyüme modellerindeki parametreler yani başlangıç anındaki mikroorganizma sayısı $\left(\log _{10} N_{0}\right)$, mikroorganizmaların ulaşabileceği azami sayı $\left(\log _{10} N_{\text {maks }}\right)$, uyum zamanı $(\lambda)$ ve azami özgül büyüme hızı $\left(\mu_{\text {maks }}\right)$ Şekil 2'de gösterilmiştir.

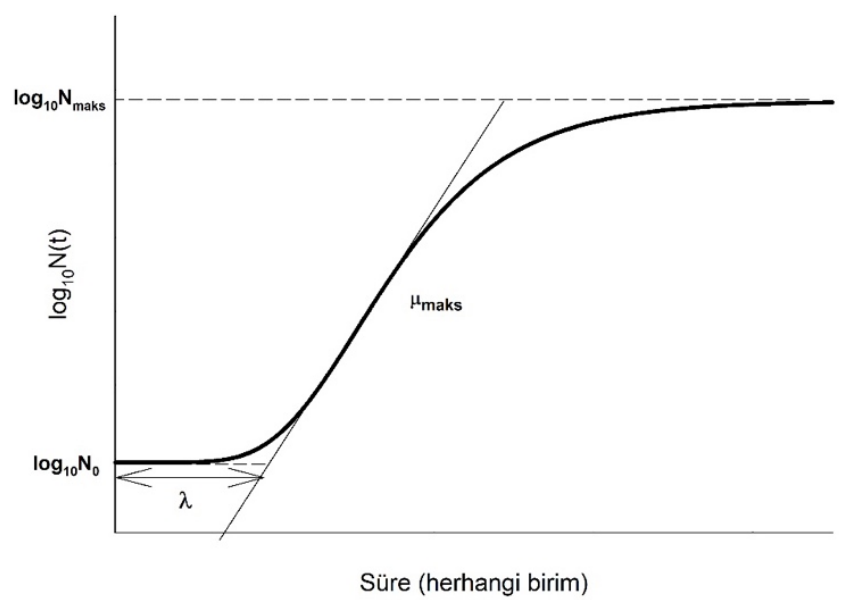

Figure 2. Demonstration of growth model parameters on the growth curve

Şekil 2. Büyüme modeli parametrelerinin büyüme ĕgrisi üzerinde gösterimi 
Buradaki parametrelerden $\log _{10} N_{0}$ ve $\log _{10} N_{\text {maks }}$ 'i grafik üzerinde gözlemlemek ve yorumlamak oldukça kolaydır. Öte yandan, azami özgül büyüme hızını tespit edebilmek için "S" şeklindeki büyüme eğrisinin dönüm noktasından çizilen doğrunun eğimi bulunmalıdır. Diğer bir deyişle en yüksek eğime sahip doğru dönüm noktasından geçen doğrudur ve bunun eğimi de $\mu^{\prime}$ maks $\left(\mu_{\text {maks }} / 2.303\right)$ olarak hesaplanabilir. Bu doğrunun $\log _{10} N_{0}$ 'dan çizilen yatay doğruyla kesiştiği yerde $\lambda$ 'dır.

\section{2. ÖK-BUZ FiT uygulamasının içerisinde yer alan büyüme modelleri}

\subsubsection{Gompertz modeli}

$\mathrm{Bu}$ model Zwietering ve ark. (1990) tarafindan türetilmiş olup, geliştirilmiş (modifiye edilmiş) Gompertz modeli olarak da geçmektedir. Model denklemi aşağıda verilmiştir (Eş.4);

$$
\log _{10} N(t)=\log _{10} N_{0}+\left(\log _{10} N_{\text {maks }}-\log _{10} N_{0}\right) \cdot \exp \left\{-\exp \left[\frac{\mu_{\text {maks }} \cdot / 2.303}{\left(\log _{10} N_{m a k s}-\log _{10} N_{0}\right)} \cdot(\lambda-t)+1\right]\right\}
$$

Burada $e=\exp (1)$ yani Euler sayısıdır (2.7182..). Görüldüğü gibi bütün büyüme modeli parametreleri $\left(\log _{10} N_{0}\right.$, $\log _{10} N_{\text {maks }}, \lambda$ ve $\mu_{\text {maks }}$ ) Gompertz denkleminde yer almaktadır.

\subsubsection{Baranyi modeli}

Baranyi ve Roberts (1994) tarafından önerilen bu model iç içe iki diferansiyel denklemden oluşmaktadır ve bu iki denklemin sabit koşullarda (örneğin sabit sıcaklıkta) çözümü şu şekildedir (Öksüz ve Buzrul, 2020) (Eş.5);

$$
\log _{10} N(t)=\log _{10} N_{\text {maks }}+\log _{10}\left[\frac{1+\exp \left[\mu_{m a k s} \cdot(t-\lambda)\right]-\exp \left(-\mu_{m a k s} \cdot \lambda\right)}{\exp \left[\mu_{m a k s} \cdot(t-\lambda)\right]-\exp \left(-\mu_{m a k s} \cdot \lambda\right)+10^{\left(\log _{10} N_{m a k s}-\log _{10} N_{0}\right)}}\right]
$$

Baranyi modelinde de tıpkı Gompertz modelindeki gibi bütün model parametreleri yer almaktadır.

\subsection{3. $\ddot{U}$ ç fazlı doğrusal model}

Bu eşitlik sistemine üç fazlı doğrusal (ÜFD) model denmesinin sebebi büyüme evrelerinin her birinin birer doğru ile tanımlanmasıdır. ÜFD modeli Buchanan ve ark. (1997) tarafından önerilmiştir ve aşağıdaki eşitlik 6 ile ifade edilebilir:

$$
\text { Ĕger } t \leq \lambda \log _{10} N(t)=\log _{10} N_{0}
$$

Ĕger $\lambda<t<t_{\text {maks }} \log _{10} N(t)=\log _{10} N_{0}+\mu / 2.303 \cdot(t-\lambda)$

Eğer $t \geq t_{\text {maks }} \log _{10} N(t)=\log _{10} N_{0}+\mu / 2.303 \cdot\left(t_{\text {maks }}-\lambda\right)$

ÜFD modelinde diğer modellerden farklı olarak iki durum göze çarpmaktadır: (i) büyüme hızı azami özgül büyüme hızı ( $\left.\mu_{\text {maks }}\right)$ olarak değil de özgül büyüme hızı $(\mu)$ olarak ifade edilmiştir. Bunun nedeni ÜFD modelinde çoğalma evresi bir doğru ile tanımlanmıştır ve doğrunun eğimi sabittir (doğrunun eğimi $\mu / 2.303$ 'tür). Oysa Gompertz ve Baranyi modellerinde çoğalma evresinin eğimi sabit değildir ve eğimin en yüksek olduğu durumda azami özgül büyüme hızı gözlemlenmektedir, (ii) $\log _{10} N_{\text {maks }}$ parametresi modelde görünmemektedir. Onun yerine $t_{\text {maks }}$ parametresi vardır. Aslında bu parametre azami sayıya yani $\log _{10} N_{\text {maks }}$ değerine ulaşıldığı zamandır ve bu modelde (Eş.7);

$$
\log _{10} N_{\text {maks }}=\log _{10} N_{0}+\mu / 2.303 \cdot\left(t_{\text {maks }}-\lambda\right) \text {. }
$$

şeklinde tanımlanmaktadır. Yani bu parametre $\left(\log _{10} N_{\text {maks }}\right)$ diğer 4 parametre $\left(\log _{10} N_{0}, t_{\text {maks }}, \lambda\right.$ ve $\left.\mu\right)$ kullanılarak hesaplanabilmektedir.

\section{3. ÖK-BUZ GRoFiT uygulamasının çalışma prensibi}

Uygulama deneysel veriler ile model uyumu arasındaki farkların ya da artıkların karesinin en aza indirilmesi (minimize edilmesi) ilkesine dayanmaktadır. Bunun için Excel'in Çözücü aracından faydalanılmaktadır (Yurdakul ve ark., 2020). Excel'de çözücü aracını yüklemek için Dosya Menüsünden; Seçenekler $>$ Eklentiler $>$ Excel Eklentileri Git’ten çözücü işaretlenmelidir. Çözücü kullanılarak model parametreleri elde edilmektedir. Aynı zamanda da model uyum göstergeleri hesaplanmaktadır. Bunlar $\mathrm{R}^{2}$, ayarlı $\mathrm{R}^{2}$ ve modelin standart hatasıdır (RMSE). 
Mikroorganizmaların Büyüme Eğrilerini Tanımlamak İçin Excel Tabanlı, Kullanıcı Dostu, Ücretsiz Bir Araç: ÖK-BUZ GRoFiT Birçok çalışmada $\mathrm{R}^{2}$ değerine bakılarak model uyumu değerlendirilir. Ancak bu yanıltıcıdır (Leylak ve ark., 2020) dolayısıyla ayarlı $\mathrm{R}^{2}$ ve RMSE değerleri de ÖK-BUZ GRoFiT uygulamasında yer almaktadır. Ayarlı $\mathrm{R}^{2}$ değeri 1'e ne kadar yakın, RMSE değeri ise 0'a ne kadar yakın olursa model uyumu o kadar iyidir. Daha sonra yine Excel'de (arka planda) 100 adet Monte Carlo (MC) benzetimi yapılarak model parametrelerinin standart hataları ve \%95 güven aralıkları (üst ve alt limitleri) hesaplanmaktadır. MC benzetimi birçok amaçla kullanılmakla birlikte bu uygulamadaki kullanım amacı parametre belirsizliklerini elde etmek içindir. $\mathrm{Bu}$ işlem kullanılan bilgisayarın hızına bağlı olarak değişmekle birlikte yaklaşık olarak 30 saniye kadar sürmektedir. MC benzetimi yapmak için birçok farklı program kullanılmakla birlikte Excel'de de MC benzetimi yapmak mümkündür (Lambert ve ark., 2012).

\subsection{Veri seti ve diğer yazılımlarla karşılaştırma}

Bu çalışmada birçok farklı veri seti denenmiştir. Bunların bir kısmı yayımlanmış çalışmalardan, bir kısmı ise Konya Gıda ve Tarım Üniversitesi, Gıda Mühendisliği laboratuvarlarında yapılan deneylerden elde edilmiştir. ÖKBUZ GRoFiT uygulamasından elde edilen sonuçlar paralı bir yazılım olan ve aynı veri setlerinin SigmaPlot'taki tanımlamaları ile karşılaştırılmıştır.

\subsection{Uygulamanın tek bir model için kullanımı ve yorumlama}

ÖK-BUZ GRoFiT uygulaması açıldığında kullanıcıyı Şekil 3'deki görünüm karşılayacaktır. Kullanıcının süre (saniye, dakika veya saat olarak) ve mikroorganizmaların süreye karşılık değişim yani $\log _{10} N(t)\left(\log _{10} \mathrm{KOB}_{\mathrm{mL}}{ }^{-1}\right.$ veya $\log _{10} \mathrm{KOB} \mathrm{g}^{-1}$ olarak) verilerini Excel'de A2 ve B2 hücrelerinden başlayarak girmesi beklenir. Şekil 4'te uygulamayı denemek için eklenen veriler görülmektedir.

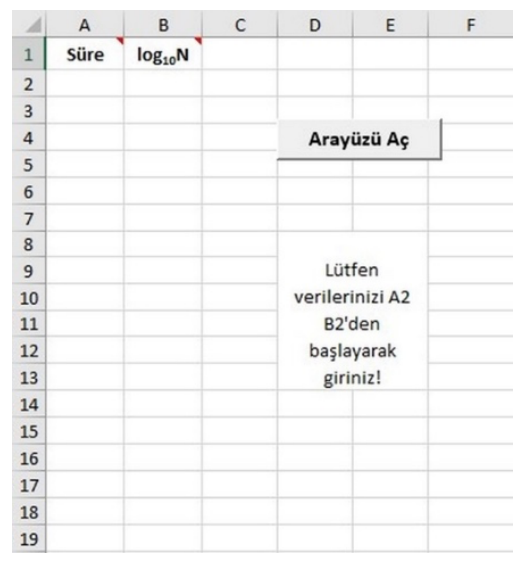

Figure 3. Splash screen of ÖK-BUZ GRoFiT Şekil 3. ÖK-BUZ GRoFiT'in açılış ekranı

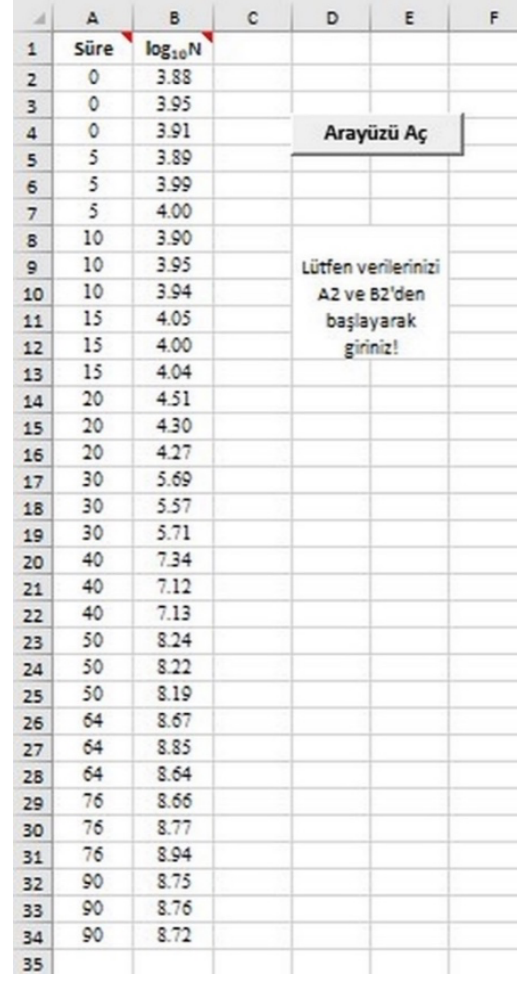

Figure 4. Entering the data to ÖK-BUZ GRoFiT. These are the growth data of Listeria monocytogenes in broth containing $9 \%$ salt at $30^{\circ} \mathrm{C}$ and taken form Lambert et al. (2012)

Şekil 4. Verilerin ÖK-BUZ GRoFiT'te girilmesi. Bu veriler Listeria monocytogenes'in \%9 tuz içeren sıvı besiyerinde, $30^{\circ} \mathrm{C}$ 'deki büyüme verileri olup, Lambert ve ark. (2012)'dan alınmıştır 
Veriler girildikten sonra "Arayüzü Aç" düğmesine tıklanır ve Şekil $5 a$ 'da görülen arayüz belirir. Buradan model seçimine gelindiğinde ise uygulama içerisinde yer alan mikrobiyal büyüme modelleri (Baranyi, Gompertz ve ÜFD) görünür (Şekil 5b). Bu modellerden herhangi birisi seçilerek "Uygula" düğmesine basıllır ve sonuçlar elde edilir.
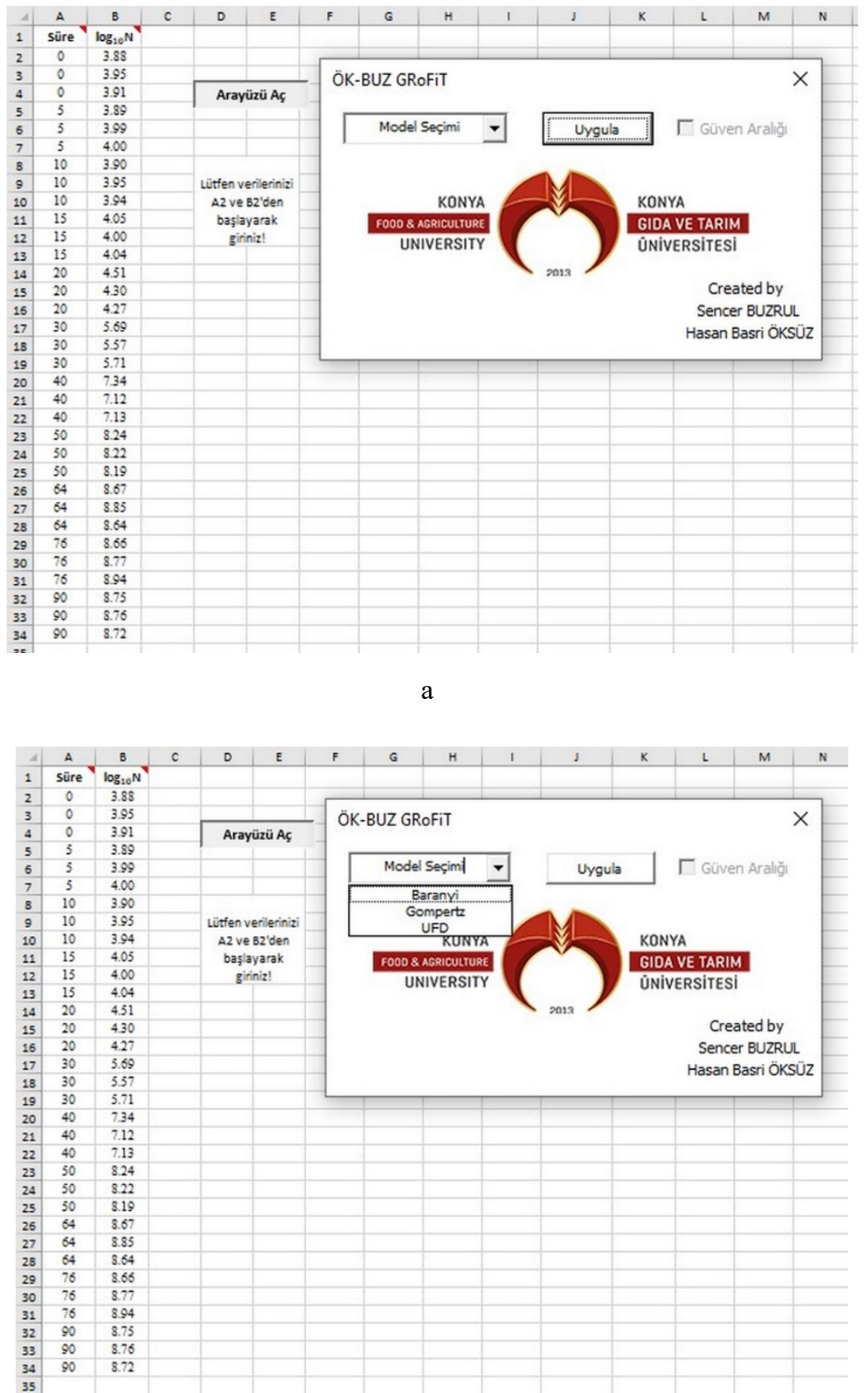

b

Figure 5. Interface appearing when clicking open the interface (b). Growth models exist in the interface (b)

\section{Şekil 5. Arayüzü Aç’a basıldlğında beliren arayüz (a). Arayüz içerisinde yer alan büyüme modelleri (b)}

Burada uygulamadaki ilk model olan Baranyi modelinin uygulaması gösterilecektir. Baranyi modeli seçilip uygulaya tıklandığında ara yüzde işlemin devam ettiğini belirten bir uyarı çıkacaktır (Şekil Ø). İşlem hızlı bilgisayarlarda yaklaşık olarak 10-15 saniye kadar sürerken yavaş bilgisayarlarda bu süre 30-40 saniyeye kadar çıkabilmektedir. İşlem sonuçlandığında ise Şekil 7'de gösterilen sonuçlar ve grafik elde edilecektir. Eğer grafik üzerinde $\% 95$ güven aralıklarının da görünmesi isteniyorsa ara yüzdeki güven aralığı onay kutusunu aktif hale 

getirmek yeterlidir. Bu durumda grafik üzerinde güven aralıkları da (siyah kesikli çizgiler) model uyumu (kırmızı düz çizgiler) ve veriler (mavi daireler) ile birlikte gösterilecektir (Şekil 8).

Elde edilen sonuçları yorumlamak ise çok zor değildir. Görüldüğü gibi verilere bakıp yaklaşık olarak da tahmin edilebilecek $\log _{10} N_{0}$ ve $\log _{10} N_{\text {maks }}$ Baranyi modeli için sırasıyla 3.91 ve 8.74 olarak bulunmuşlardır. Uyum zamanı 17.90 dakika, azami özgül büyüme hızı ise 0.3318 dakika $^{-1}$ olarak elde edilmiştir. Bununla birlikte uygulama arka planda MC benzetimi yaparak model parametrelerinin standart hatalarını, $95 \%$ alt ve üst limitlerini de hesaplamıştır. Standart hataların parametre değerinden oldukça küçük olması parametrelerin istatistiksel olarak da anlamlı olduğunun göstergesidir. Dikkat edilecek olursa alt ve üst limitlerin simetrik olmadığı anlaşılacaktır. Bu doğrusal olmayan regresyonun doğal bir sonucudur. Örneğin uyum zamanı 17.90 dakika olarak bulunurken \%95 alt limit 1.70 eksiğiyle 16.20 dakika olarak, \%95 üst limit ise 1.10 fazlasıyla 19.00 dakika olarak hesaplanmıştır. Bunun anlamı şudur elde edilen parametre değeri yani 17.90, \%95 ihtimalle 16.20 ile 19.00 arasındadır. Diğer bir deyişle bu aralıkta olmama ihtimali sadece $\% 5$ 'tir!

ÖK-BUZ GRoFiT $\quad X$

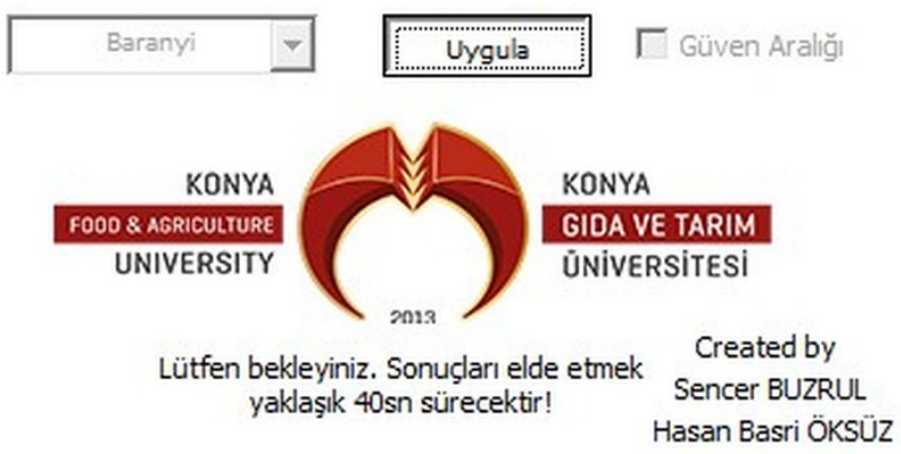

Figure 6. Remark indicating the process is in progress

Şekil 6. İşlemin devam ettiğini belirten uyart

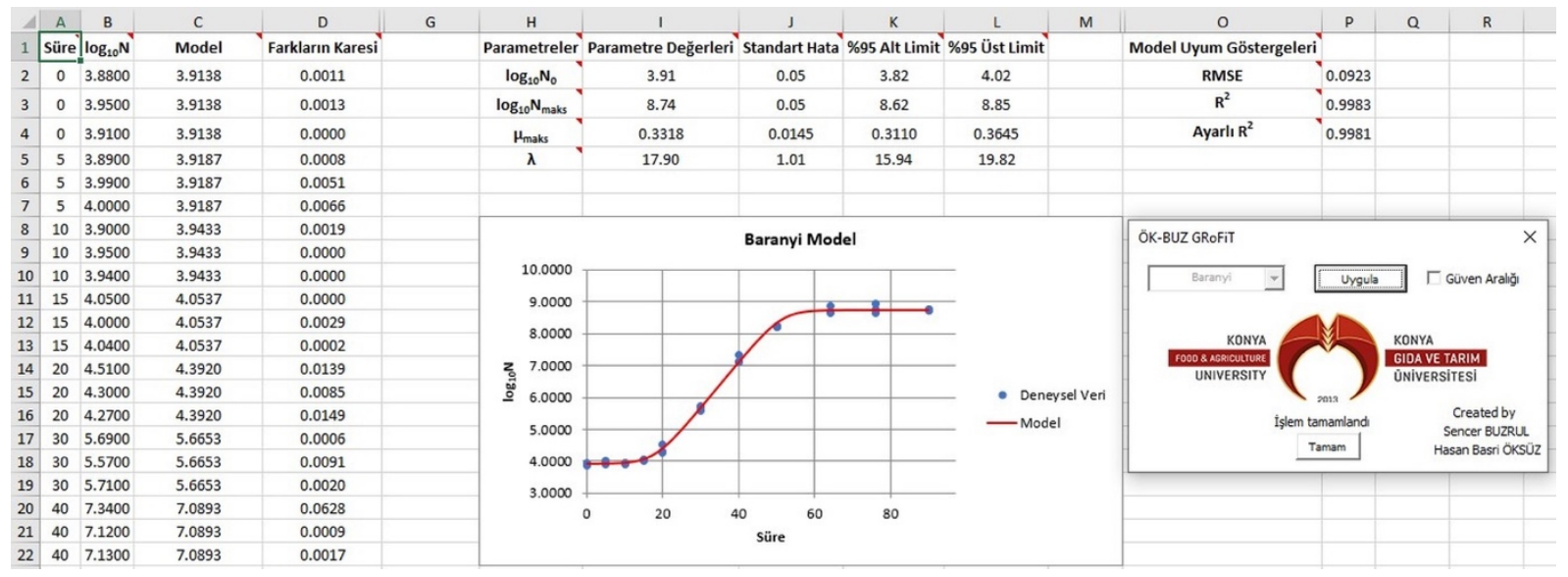

Figure 7. Results of the Baranyi model

Şekil 7. Baranyi modelinin sonuçları

Model uyum göstergelerine bakıldığında yüksek ve 1'e yakın $R^{2}(0.9983)$ ve ayarlı $R^{2}(0.9981)$ ile düşük ve 0’a yakın RMSE (0.0923) değeri olduğu görülebilir. Bu da modelin veri için oldukça uygun olduğunu göstermektedir. Bu uyum grafikten de görsel olarak anlaşılabilmektedir (Şekil 8). Dahası grafik üzerinde gösterilen \%95 güven aralıkları modelin uyumunu doğrulamaktadır. Model (kırmızı düz çizgiler) \%95 ihtimalle kesikli siyah çizgilerle gösterilen güven aralıklarının içerisinde olacaktır. 
JOTAF/ Journal of Tekirdag Agricultural Faculty, 2021, 18(3)

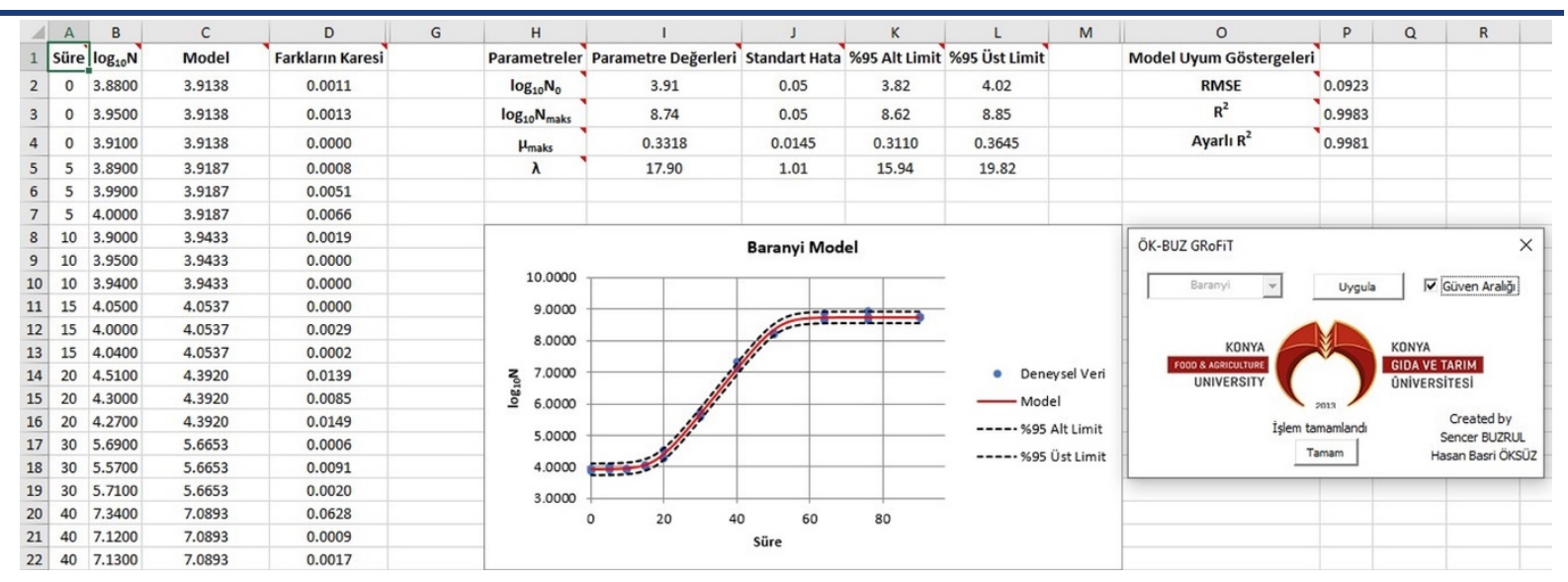

Figure 8. Demonstration of 95\% confidence limits on the graph for the fitted in Figure 7

Şekil 8. Şekil 7’de uygulanan modelin grafik üzerinde \%95 güven aralıklarının gösterilmesi

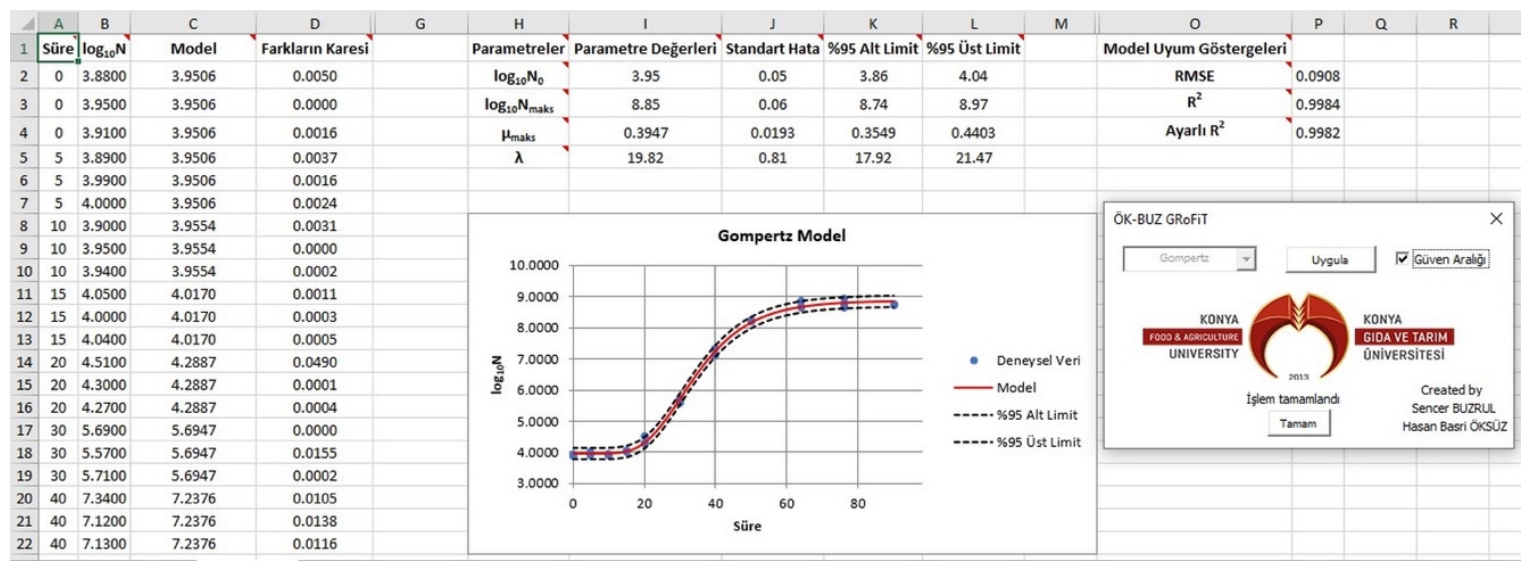

Figure 9. Results of the Gompertz model

Şekil 9. Gompertz modelinin sonuçları

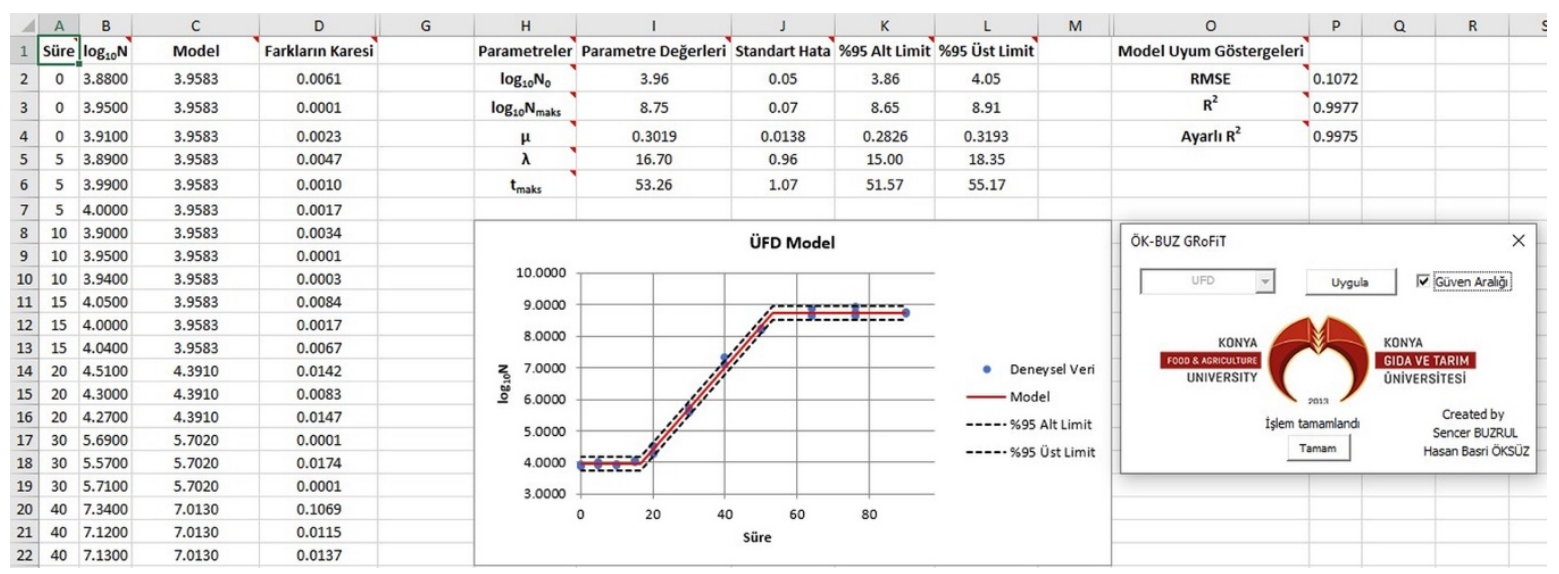

Figure 10. Results of the three phase linear (TPL) model

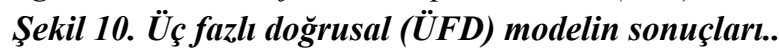

\subsection{Aynı veri setine farklı modellerin uygulanarak karşılaștırılması}

$\mathrm{Bu}$ bölümde aynı veri setine araç içerisinde yer alan diğer modellerin uygulanışı ve karşılaştırılması gösterilecektir. Şekil 4'te gösterilen verilere Gompertz ve ÜFD modellerinin uygulanması neticesinde sırasıyla Şekil 9 ve Şekil 10'da gösterilen sonuçlar elde edilmiştir. Uygulanan her üç modelin RMSE değerine bakıldığında 
[RMSE değeri en önemli ve en doğru model uyum göstergesidir (Ratkowsky, 2004)] en düşük olan Gompertz modelidir. Dolayısıyla bu veri seti için en uyumlu sonuçlar sırasıyla Gompertz, Baranyi ve ÜFD modelleridir. Ancak bu sıralama farklı veri setleri için değişecektir. Her üç modelin parametre değerleri karşılaştırıldığında birbirlerine yakın $\log _{10} N_{0}$ ve $\log _{10} N_{\text {maks }}$ değerleri elde edildiği görülebilir (Şekiller 8,9 ve 10). Öte yandan Gompertz modelinin en yüksek $\lambda$ ve $\mu_{\text {maks }}$ parametrelerini elde ettiği görülmüştür. Aslında bu durum Gompertz modeli için hep eleştiri konusu olmuştur (Dalgaard, 1995; McKellar ve Knight, 2000; Membré ve ark., 1999; Whiting ve Cygnarowicz-Provost, 1992). Dolayısıyla son yıllarda Baranyi modelinin yaygınlaşmasında ve Gompertz modelinin önüne geçmesinde bu eleştirilerin önemli bir katkısı olmuştur.

\section{3. ÖK-BUZ GRoFiT uygulamasının ücretli bir yazılımla karşılaştırılması}

Uygulamanın her üç model için de ücretli bir yazılım olan SigmaPlot (Versiyon 12.0) programı ile farklı veri setleri (toplamda 20 farklı veri seti denenmiştir.) için karşılaştırılması yapılmıştır. Sonuçlar göstermektedir ki parametre değerleri ile model uyum göstergeleri $\left(\mathrm{R}^{2}\right.$, ayarlı $\mathrm{R}^{2}$ ve RMSE) birebir aynıdır ve bu şaşırtıcı değildir çünkü SigmaPlot programı da Excel çözücü de farkların (ya da artıkların) karelerinin toplamını en aza indirgemeye çalışarak parametre değerlerini elde etmektedirler. Ancak, SigmaPlot Marquardt-Levenberg algoritmasını, Excel çözücü ise genelleştirilmiş-azaltılmış fark yöntemini kullanarak bunu gerçekleştirmektedir. Yani, Excel çözücü uygulaması ile doğrusal olmayan regresyon yapmak ve diğer paralı yazılımlar ile aynı sonucu elde etmek mümkündür (Yurdakul ve ark., 2020) fakat SigmaPlot programında parametrelerin standart hata değerleri ÖKBUZ GRoFiT'e göre daha düşük hesaplanmıştır (gösterilmeyen sonuçlar). Bunun nedeni ise standart hata hesaplamasında ÖK-BUZ GRoFiT uygulamasının MC benzetimi yapması SigmaPlot programının ise varyanskovaryans matriksini kullanmasıdır. Ancak, doğrusal olmayan modellerde bu yöntemin kullanılması standart hataların olduğundan daha az hesaplanmasına yol açacaktır (Geereard ve ark., 2005). Bu da SigmaPlot programının neden daha düşük parametre standart hatalarını hesapladığını açıklamaktadır. Ayrıca ÖK-BUZ GRoFiT uygulaması ile parametrelerin $\% 95$ alt ve üst limitleri de elde edilebilirken SigmaPlot bu değerleri vermemektedir. Yine de kullanıcının bunu hesaplaması mümkündür. Ancak unutulmamalıdır ki bu hesaplama simetrik olacaktır. Yani, parametre değeri \pm güven aralığı şeklinde hesaplanabilecektir. Fakat yukarıda da değinildiği gibi doğrusal olmayan regresyonda güven aralıkları simetrik olmayacağından ÖK-BUZ GRoFiT uygulamasının MC benzetimi sonucu elde ettiği parametre üst ve alt limitleri SigmaPlot uygulamasına göre avantajlı görünmektedir.

SigmaPlot programının ÖK-BUZ GRoFiT’e göre avantajlı yanı ise parametrelerinin istatistiksel olarak anlamlı olup olmadığını gösteren p-değerini de hesaplamasıdır. Ancak, ÖK-BUZ GRoFiT uygulamasında parametre değerine ve ilgili parametre değerinin standart hatasına bakarak da o parametrenin istatistiksel olarak anlamlı olup olmadığını az çok tahmin etmek mümkündür. Örneğin parametre değerinin \%20'sinden daha fazla bir standart hata değeri, ilgili parametrenin istatistiksel olarak anlamsız olabileceğini göstermektedir (Motulsky ve Christopoulos, 2003).

\section{Sonuç}

$\mathrm{Bu}$ çalışmada internetten ücretsiz olarak indirilerek kullanılabilen Excel tabanlı ÖK-BUZ GRoFiT uygulamasının kullanımı gösterilmiştir. Bu uygulama ile mikroorganizmaların kapalı bir ortamda (örneğin bir gıdada) büyümeleri 3 farklı model ile tanımlanabilir. Parametre değerleri, bunların belirsizlikleri (standart hata, $\% 95$ üst ve alt limitleri) ve model uyum göstergeleri bulunabilir.

Uygulamayı kullanırken dikkat edilmesi gereken bazı hususlar bulunmaktadır. Örneğin en az 12-15 veriye sahip her üç evrenin de (uyum, büyüme ve durma) gözlemlenebildiği veri seti girilmelidir. Daha az veriye sahip bir set girildiğinde bile sonuç almak mümkündür. Ancak, böyle bir durumda parametrelerin standart hatası yüksek, hatta bazen parametrenin kendisinden bile büyük çıkabilir ki bu istenmeyen bir durumdur. Dahası, aynı veri setine aynı modeli birden fazla uygulamak mümkündür. Bu uygulamaların tamamında model parametreleri ve model uyum göstergeleri aynı çıkacaktır. Fakat parametrelerin standart hataları ile \%95 üst ve alt limit değerleri farklı çıkabilir. Bu oldukça normal bir durumdur çünkü ÖK-BUZ GRoFiT her seferinde farklı bir MC benzetimi yaparak bunları hesaplamaktadır. Burada unutulmaması gereken konu çıkan her bir sonuç için parametre değerlerinin \%95 ihtimalle uygulamada hesaplanan üst ve alt limit değerleri arasında olacağıdır. 
Söz konusu uygulamayı kullanmak için ileri düzeyde bir modelleme bilgisine sahip olmaya gerek yoktur. Az da olsa Excel kullanımına aşina olan hemen herkes bu uygulamayı rahatlıkla kullanabilir. Ayrıca bu uygulama sadece mikrobiyal büyüme için değil gıda veya başka disiplinlerde yer alan S-şeklindeki (örneğin kristalizasyon kinetiği) tüm eğrileri tanımlamak için kullanılabilir. İleride, kullanıcılardan gelecek olan yorumlar ile birlikte, yeni büyüme modellerinin de ÖK-BUZ GRoFiT uygulamasına eklenmesi düşünülmektedir. Ayrıca, uygulamanın İngilizce sürümü için de çalışmaların başlatılması düşünülmektedir.

\section{Teșekkür}

ÖK-BUZ GRoFiT yazılımının içerisindeki logo kullanımındaki ve uygulamanın web sitesine yerleştirilmesindeki yardımlarından dolayı Zeki ÖZER'e teşekkür ederiz. 


\section{Kaynakça}

Arıcı, M. (2006). Gıda muhafazasında yüksek hidrostatik basıncın mikroorganizmalar üzerinde etkisi. Tekirda ̌̆ Ziraat Fakültesi Dergisi 3(1): 41-49.

Baranyi, J., Roberts, T.A. (1994). A dynamic approach to predicting bacterial growth in food. International Journal of Food Microbiology 23 (3-4): 277-294.

Buchanan, R.L., Whiting, R.C., Damert, W.C. (1997). When is simple good enough: a comparison of the Gompertz, Baranyi, and three-phase linear models for fitting bacterial growth curves. Food Microbiology 14 (4): 313-326.

Dalgaard, P. (1995). Modelling of microbial activity and prediction of shelf life for packed fresh fish. International Journal of Food Microbiology 26 (3): 305-317.

Fujikawa, H., Kano, Y. (2009). Development of a program to fit data to a new logistic model for microbial growth. Biocontrol Science 14 (2): 83-86.

Geeraerd, A.H., Valdramidis, V.P., Van Impe, J.F. (2005). GInaFiT, a freeware tool to assess non-log-linear microbial survivor curves International Journal of Food Microbiology 102 (1): 95- 105.

Lambert, R.J.W., Mytilinaios, I., Maitland, L., Brown, A.M. (2012). Monte Carlo simulation of parameter confidence intervals for non-linear regression analysis of biological data using Microsoft Excel. Computer Methods and Programs in Biomedicine 107 (2): $155-163$.

Leylak, C., Yurdakul, M., Buzrul, S. (2020). Gıda bilimlerinde Excel kullanımı 1: Doğrusal regresyon. Food and Health 6 (3): $186-198$.

McKellar, R.C., Knight, K. (2000). A combined discrete-continuous model describing the lag phase of Listeria monocytogenes. International Journal of Food Microbiology 54 (3): 171-180.

Membré J.M., Ross, T., McMeekin, T. (1999). Behaviour of Listeria monocytogenes under combined chilling processes. Letters in Applied Microbiology 28 (3): 216-220.

Motulsky, H., Christopoulos, A. (2003). Fitting models to biological data using linear and nonlinear regression. A practical guide to curve fitting. GraphPad Software Inc., San Diego CA, pp. 249.

Niyaz, Ö., Demirbaş, N. (2018). Food Safety Perceptions of Fresh Fruits and Vegetables Consumers. Journal of Tekirdag Agricultural Faculty 15(2): 36-44.

Öksüz, H., Buzrul, S. (2020). Monte Carlo analysis for microbial growth curves. Journal of Microbiology, Biotechnology and Food Sciences 10 (3): 418-423.

Özçelik, F., Halkman, A.K., Bağder-Elmacı, S. (2019). Mikroorganizma gelişmesi. In: Halkman, A.K. (Ed.) Gıda Mikrobiyolojisi.Başak Mtabaacılık ve Tanıtım Hizmetleri Ltd., Ankara, ISBN: 978-605-245-683-5, pp. 23-60. Bölüm 2.

Ratkowsky, D.A. (2004). Model fitting and uncertainty. In: McKellar, R., Lu, X. (Eds.), Modeling Microbial Responses in Foods. CRC Press, Boca Raton, ISBN: 0-8493-1237-X, pp. 151- 196. Chapter 4.

Whiting, R., Cygnarowicz-Provost, M. (1992). A quantitative model for bacterial growth and decline. Food Microbiology 9 (4): $269-277$.

Yurdakul, M., Leylak, C., Buzrul, S. (2020). Gıda bilimlerinde Excel kullanımı 2: Doğrusal olmayan regresyon. Food and Health 6 (3): 199212.

Zwietering, M.H., Jongenburger, I., Rombouts, F.M., Van't Riet. K. (1990). Modelling of the bacterial growth curve. Applied and Environmental Microbiology 56 (6): 1875-1881. 